\title{
Rapid Screening of Musa Species for Resistance to Black Leaf Streak Using In Vitro Plantlets in Tubes and Detached Leaves
}

\author{
M. Twizeyimana, International Institute of Tropical Agriculture (IITA), PMB 5320, Ibadan, Nigeria and Department \\ of Crop Protection and Environmental Biology, University of Ibadan, Ibadan, Nigeria; P. S. Ojiambo, IITA, PMB \\ 5320, Ibadan, Nigeria; A. Tenkouano, IITA, Humid Forest Ecoregional Center, BP 2008, Yaounde, Cameroon; \\ T. Ikotun, Department of Crop Protection and Environmental Biology, University of Ibadan, Ibadan, Nigeria; and \\ R. Bandyopadhyay, IITA, PMB 5320, Ibadan, Nigeria
}

\begin{abstract}
Twizeyimana, M., Ojiambo, P. S., Tenkouano, A., Ikotun, T., and Bandyopadhyay, R. 2007. Rapid screening of Musa species for resistance to black leaf streak using in vitro plantlets in tubes and detached leaves. Plant Dis. 91:308-314.

This study investigated the utility of inoculation of in vitro plantlets in tubes and detached leaves as reliable and rapid assays for screening Musa genotypes against Mycosphaerella fijiensis, the causal agent of black leaf streak. In the first part of the study, three types of inocula were evaluated to determine suitability for in vitro inoculation. Inoculation of in vitro plantlets with mycelial fragments resulted in significantly $(P<0.05)$ higher levels of disease severity and faster rates of disease progress compared with inoculations using conidial suspensions. In the detached leaf assay, amending agar medium with plant hormones significantly $(P<0.0001)$ aided retention of green leaf color. Leaf pieces on medium containing gibberellic acid at $5 \mathrm{mg} / \mathrm{liter}$ had about $5 \%$ chlorosis at 52 days after plating. When in vitro plantlets in tubes and detached leaves of 10 Musa genotypes with different levels of disease resistance were inoculated with M. fijiensis, there were significant $(P<0.05)$ differences among genotypes in leaf area infected, incubation time, and symptom evolution time. For incubation time and leaf area infected, cultivars responded depending on their level of disease resistance, with resistant genotypes Calcutta-4 and PITA-17 having significantly $(P=0.001)$ longer incubation times and lower infected leaf areas compared with the susceptible cultivar Agbagba and moderately resistant cultivar FHIA-23. A similar pattern in cultivar response was observed for symptom evolution time. Leaf area infected was not significantly $(P=0.2817$ for two-tailed $t$ test) different when assessed using the two assays, and infected leaf areas in both assays were strongly correlated $(r=0.88, n=48, P<$ $0.0001)$. Although incubation times were significantly $(P=0.0062$ for two-tailed $t$ test) different between the two assays, values from the two assays were strongly correlated $(r=0.69, n=48, P$ $<0.0001)$. These results show that these two assays are rapid and space-effective, and can reliably be used for screening Musa genotypes for resistance to black leaf streak.
\end{abstract}

Additional keywords: banana, black Sigatoka, plantain

Black leaf streak, caused by $M y$ cosphaerella fijiensis Morelet (teleomorph of Pseudocercospora fijiensis (Morelet) Deighton), is regarded as the most damaging and economically important leaf disease of bananas and plantains worldwide $(5,16)$. In 1980, chemical control of black leaf streak, also known as black Sigatoka, accounted for $27 \%$ of total production costs in commercial plantations (27). The fungus reduces the green leaf area and impedes photosynthesis, which is needed for fruit filling (16). In highly susceptible varieties, the disease can lead to the total collapse of the plant. Although black leaf streak significantly reduces yield, the

Corresponding author: R. Bandyopadhyay

E-mail: r.bandyopadhyay@cgiar.org

Accepted for publication 19 October 2006.

DOI: 10.1094/PDIS-91-3-0308

(C) 2007 The American Phytopathological Society greatest loss occurs as a result of premature ripening of fruits in the field and during transportation and storage (15). Mobambo et al. (17) reported minimum yield loss of $33 \%$, and greater losses may occur if control measures are either not adopted or fail $(7,16)$.

Chemical control and breeding for black leaf streak resistance remain the two dominant strategies to control the disease $(11,16,23)$. Although fungicides are the most widely used option in large commercial banana plantations, systemic fungicides pose a risk of resistance development in the pathogen population (6). For most subsistence producers of bananas and plantains, use of fungicides is impractical (7). For commercial growers, banana genotypes resistant to black leaf streak may not be a priority, but breeding for resistance is a more environmentally friendly method.

For many years, resistance to black Sigatoka has been the main focus in breeding programs (25). Screening for resistance requires methods to unambiguously dis- criminate resistant and susceptible genotypes at different stages of plant development. Field evaluation under natural infection conditions was initially the only method for screening banana cultivars (9), but it is cumbersome, time-consuming, and expensive (4). Although field performance of genotypes remains the benchmark for evaluating host plant resistance, epidemiological characteristics of black leaf streak make field evaluation unsuitable as a rapid and early screening method. Early evaluation under controlled conditions using artificial inoculation is an important requirement to screen large numbers of Musa spp. for resistance to black leaf streak (11). Evaluation with artificial inoculation allows for standard inoculum pressure that ensures uniform disease development on test genotypes.

Mobambo et al. (18) reported an early field screening method using natural inoculum on tissue-cultured Musa plants, but the method presents difficulties in maintaining uniform disease pressure and is time-consuming. Inoculation of in vitro propagated Musa plants with mycelial and conidial suspensions has also been used to screen genotypes under greenhouse conditions $(4,10)$. However, this method produces variable results (11) and limits the number of genotypes that can be screened. In vitro plantlets (13) and detached leaves $(8,14)$ have been used for rapid screening of genotypes for disease resistance. However, no published studies have been conducted to screen Musa spp. for resistance to black leaf streak using detached leaves or in vitro plantlets. Therefore, the main objective of this study was to evaluate the use of detached leaves and in vitro plantlets in tubes as reliable methods for rapid screening of Musa genotypes for resistance to black leaf streak. These methods are valuable tools for rapid and mass screening of Musa spp. when breeding for black leaf streak resistance.

\section{MATERIALS AND METHODS}

Plant materials. Musa genotypes with different levels of field resistance to $M$. fijiensis were used to evaluate inoculation of in vitro plantlets in tubes and detached leaves for resistance to black leaf streak. Among the plant materials (Table 1) used in this study, Agbagba (False Horn plan- 
tain) is highly susceptible, Calcutta-4 is highly resistant, and PITA-17 is resistant to M. fijiensis. The remaining cultivars, FHIA-23, FHIA-25, PITA-21, TMB2 $\times$ 24203-14, TMB2 × 25291-S26, TM3 $\times$ 26388-1, and TMB2 × 25291-S44 have intermediate levels of resistance to black leaf streak.

Inoculum preparation. Leaves of the cultivar FHIA-23 showing typical symptoms of black leaf streak and containing pseudothecia on lesions were collected from the International Institute of Tropical Agriculture (IITA)'s research farm in Onne $\left(4^{\circ} 43^{\prime} \mathrm{N}, 7^{\circ} 01^{\prime} \mathrm{E}, 10 \mathrm{~m}\right.$ altitude above sea level), Nigeria. Protocols for isolating $M$. fijiensis from diseased leaves were described earlier (26). Briefly, leaf fragments bearing stage 6 necrosis were placed in moist bags for $48 \mathrm{~h}$ to allow maturation of pseudothecia. Pieces of leaves with mature pseudothecia were stapled on 9-cmdiameter filter paper disks, dipped in sterile water for $5 \mathrm{~min}$, and placed inside the lids of petri dishes. The lids were then placed on petri dishes containing $3 \%$ water agar. Within an hour, the ascospores forcibly discharged on the agar surface. Single germinating ascospores were transferred onto V8 juice agar after $24 \mathrm{~h}$. Plates were incubated at 19 to $20^{\circ} \mathrm{C}$ under continuous UV light for pathogen development. Cultures started to produce conidia approximately 26 days later.

Mycelial fragments and conidial suspensions were used as inoculum. Prior to sporulation of cultures, mycelium was scraped and fragments were ground in sterile distilled water using a pestle for about $2 \mathrm{~min}$. The mixture was filtered through two layers of cheesecloth and then stirred. A drop of Tween 80 was added, and using a hemacytometer, the suspension was adjusted with sterile distilled water to a concentration of $1 \times 10^{6}$ mycelial fragments/ml. For conidial suspensions, sterile distilled water was added to V8 agar on petri plates following sporulation of the fungus, and the spore suspension was filtered through two layers of cheesecloth. A drop of $97 \%$ Tween 80 was added to the resulting spore suspension, and using four hemacytometer counts, sterile distilled water was added to adjust spore concentrations to $1 \times 10^{4}$ or $5 \times 10^{5}$ conidia $/ \mathrm{ml}$. Prior to inoculation, a drop of $1 \%$ Triton $\mathrm{X}-100$ was added to the inoculum suspension to enable mycelia and spores to adhere to the leaf surface.

In vitro inoculation of plantlets in tubes. Two experiments were conducted to evaluate inoculation of in vitro plantlets in tubes. In the first experiment, selected cultivars were used to establish a suitable inoculum type and concentration. Based on the results, a second experiment evaluated reactions of Musa cultivars to M. fijiensis following inoculation of in vitro plantlets in tubes.

Preparation of plantlets for in vitro inoculation followed shoot-tip culture protocols described previously (28). Briefly, to initiate cultures, $1 \mathrm{~cm}^{3}$ pieces containing the apices were excised from suckers and surface-sterilized in $95 \%$ ethanol for $15 \mathrm{~s}$, followed by soaking for $15 \mathrm{~min}$ in $0.75 \%$ $\mathrm{NaOCl}$ solution to which a drop of Tween 20 was added per $50 \mathrm{ml}$, and then rinsed three times with sterile distilled water. Shoot tips 1 to $2 \mathrm{~mm}$ in length with 2 to 4 leaf primordia were isolated aseptically and placed on modified Murashige and Skoog medium basal salt mixture supplemented with $30 \mathrm{~g} /$ liter sucrose and 0.4 $\mathrm{mg} /$ liter thiamine. Cultures were maintained at 28 to $30^{\circ} \mathrm{C}$ on a $12 / 12-\mathrm{h}$ light/dark cycle. Shoot tips and meristem were induced to proliferate by adding 0.18 $\mathrm{mg} / \mathrm{liter}$ indole acetic acid (IAA) and 4.5 $\mathrm{mg} /$ liter benzylaminopurine (BAP) to the basal medium. Plant regeneration was accomplished on the same basal medium supplemented with $0.19 \mathrm{mg} / \mathrm{liter}$ naphthalene acetic acid (NAA) and $0.23 \mathrm{mg} / \mathrm{liter}$ BAP. It took 7 to 10 weeks to establish rooted plantlets from isolated shoot tips and about 3 weeks for in vitro plantlets to develop enough leaf material for inoculation.

In the first experiment to determine a suitable inoculum type, three largest leaves of each in vitro plantlet of Agbagba, Calcutta-4, FHIA-23, and PITA-17 were inoculated (1 spot per leaf) by pipetting 40$\mu \mathrm{l}$ droplets of $1 \times 10^{6}$ mycelial fragments $/ \mathrm{ml}$ and spore suspensions of $1 \times 10^{4}$ or $5 \times 10^{5}$ conidia $/ \mathrm{ml}$. Droplets were placed carefully to avoid trickling from the leaves to the plant growth medium, on which the pathogen can grow well and kill the plantlets. Leaves touching the inner wall or the lid of the tube or the medium were excluded from inoculation. In the second experiment, plantlets of Agbagba, Calcutta-4, FHIA-23, FHIA-25, PITA-17, PITA-21, TMB2 × 24203-14, TMB2 $\times$ 25291-S26, TMB $2 \times 25291-S 44$, and TM3 $\times 26388-1$ were inoculated as described above, except that spore concentration was $5 \times 10^{5}$ conidia/ml. This spore concentration was adopted for inoculation based on the results obtained in the first experiment. In both experiments, the inoculated plantlets were incubated at $25^{\circ} \mathrm{C}$ with a $12 / 12-\mathrm{h}$ light/dark cycle for disease development. Both experiments were laid out in a completely randomized design with three replications and were conducted twice.

Observations on inoculated leaves were made from 2 to 32 days after inoculation and included incubation time, leaf area infected (\%), symptom evolution time, and stages of symptoms. Incubation time is defined as the time between inoculation and appearance of the first symptoms (stage 1), whereas symptom evolution time is defined as number of days between stage 1 and occurrence of mature lesions (stage 6). Symptom stages were recorded as described by Fouré (9): stage 1, first visible symptoms are yellowish specks $<1$ $\mathrm{mm}$ diameter on abaxial surface of the leaf; stage 2, initial speck elongates and widens to form a reddish brown streak up to $2 \mathrm{~mm}$ long and streaks are visible on both sides of the leaf; stage 3, red-brown streaks reach 20 to $30 \mathrm{~mm}$ long and color starts to change from red to dark brown; stage 4 , streak broadens and develops into an elliptical spot, dark brown on abaxial surface and black on adaxial surface of the leaf; stage 5, central area of the dark spot becomes totally black and necrotic, lesion is slightly depressed, and the black spot is surrounded by a bright yellow halo; and stage 6, center of spot dries out, fades, and becomes whitish to gray, and the spot is surrounded by a dark brown to black border and further depressed.

Table 1. Description of Musa cultivars evaluated using two techniques developed for rapid screening of germ plasm for resistance to black leaf streak caused by Mycosphaerella fijiensis

\begin{tabular}{|c|c|c|c|c|c|}
\hline Cultivars & Originy & Genome & Parents & Subgroup & Reaction \\
\hline Agbagba & Nigeria & $\mathrm{AAB}$ & Landrace & Plantain & Susceptible \\
\hline PITA-17 & IITA, Nigeria & AAAB & B. Tannap $\times$ Calcutta- 4 & Plantain & Resistant \\
\hline Calcutta-4 & India & AA & Landrace & Banana & Resistant \\
\hline FHIA-23 & FHIA, Honduras & AAAA & Highgate $\times$ SH3362 & Cavendish & Intermediate \\
\hline PITA-21 & IITA, Nigeria & AAA & $\mathrm{TMP} \times 1658-4 \times \mathrm{TMP} 2 \times 2829-62$ & Plantain & Intermediate \\
\hline TMB $2 \times 24203-14$ & IITA, Nigeria & $\ldots{ }^{\mathrm{z}}$ & TMP2 $2 \times 1448-1 \times$ TMB $\times 5295-1$ & Banana & Intermediate \\
\hline FHIA-25 & FHIA, Honduras & AAA & $\ldots$ & Cavendish & Intermediate \\
\hline TMB2 $\times 25291-S 26$ & IITA, Nigeria & AA & TMP $2 \times 2829-62 \times$ TMB $2 \times 9128-3$ & Banana & Intermediate \\
\hline TMB2 $\times 25291-S 44$ & IITA, Nigeria & $\ldots$ & TMP $2 \times 2829-62 \times$ TMB $2 \times 9128-3$ & Banana & Intermediate \\
\hline TM3 × 26388-1 & IITA, Nigeria & $\mathrm{AAB}$ & $\mathrm{TMP} \times 7002-1 \times \mathrm{TMP} 2 \times 1518-4$ & Plantain & Intermediate \\
\hline
\end{tabular}

y IITA refers to International Institute of Tropical Agriculture. FHIA refers to Fundacion Hondureña de Investigación Agricola.

${ }^{\mathrm{z}}$ Data not available. 
Detached leaf assay. A problem encountered using detached leaves in growth chambers has been inability to maintain green color in leaves for 45 to 52 days required to differentiate disease severity levels among cultivars. There- fore, the first experiment was designed to amend agar medium to prolong the green color of detached leaves. In the second experiment, once a suitable plant hormone (for plating medium) was identified, cultivars were screened for their
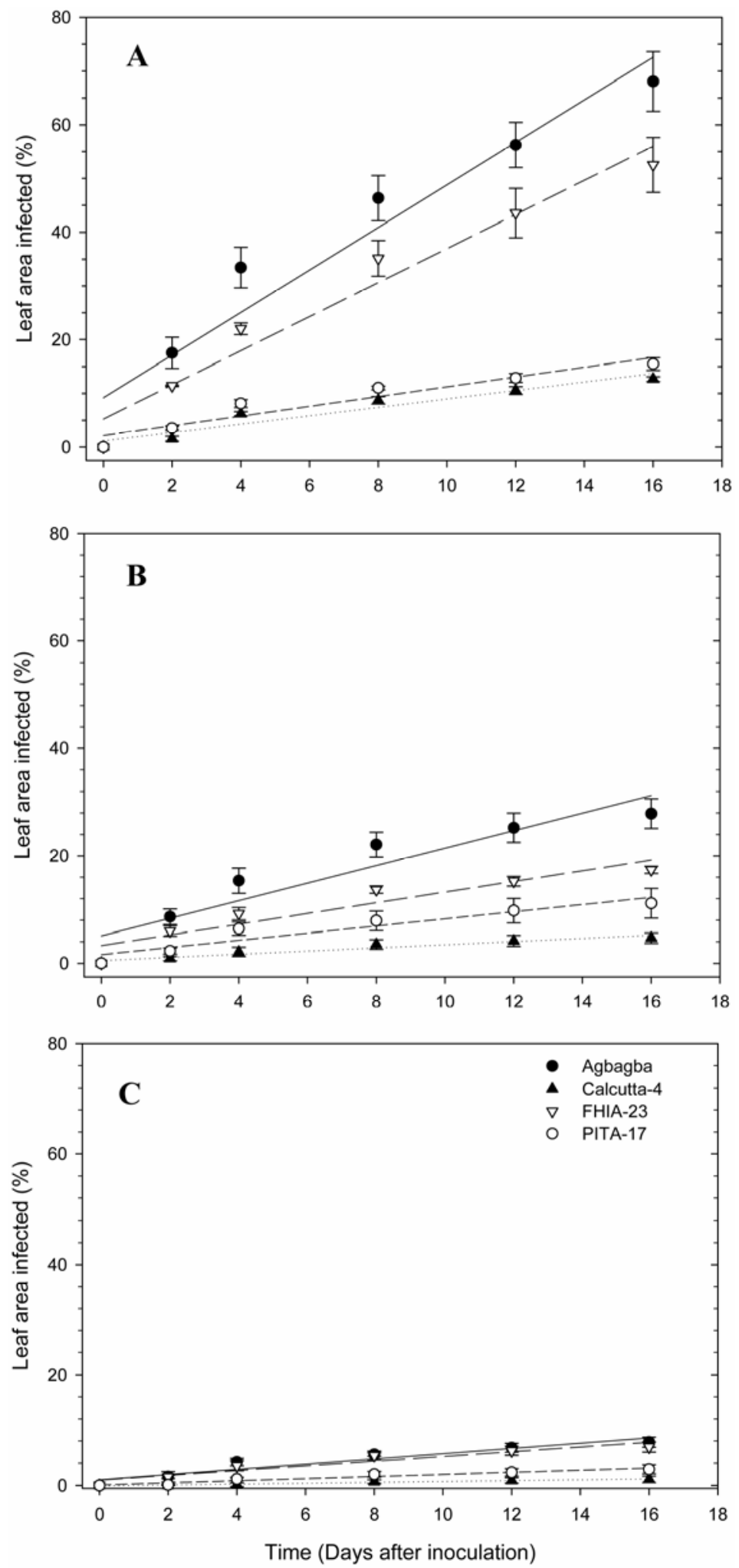

Fig. 1. Progress of black leaf streak on in vitro Musa plantlets in tubes of four cultivars inoculated with mycelia fragments (A), and conidial suspensions of Mycosphaerella fijiensis at $5 \times 10^{5}(\mathbf{B})$ and $1 \times 10^{4}$ (C) conidia/ml. For each cultivar, each data point represents the observed disease severity value, the lines represent the predicted linear disease severity values, and vertical bars represent the standard error of the observed mean disease severity value.

disease reaction using the detached leaf assay.

In the first experiment, leaves of Agbagba were collected from IITA's banana and plantain farm in Ibadan. Large leaf pieces were cut from detached leaves, surface-sterilized in $1 \% \mathrm{NaOCl}$ solution for $90 \mathrm{~s}$, and washed in 5 to 6 changes of sterile distilled water. Thereafter, smaller pieces were cut with each piece measuring $4 \mathrm{~cm}$ long $\times 3 \mathrm{~cm}$ wide. Two of these pieces were placed in plastic petri dishes with adaxial side on $1 \%$ agar technical (Oxoid, Unipath Ltd., Basingstoke, Hampshire, England) amended with plant hormones. Plant hormones evaluated in the agar medium were gibberellic acid, cytokinin, and benzimidazole, each with three different concentrations. The concentrations tested were 5,8 , and $15 \mathrm{mg} /$ liter for gibberellic acid, 10,20 , and $50 \mathrm{mg} / \mathrm{liter}$ for cytokinin, and 20, 40, and $60 \mathrm{mg} / \mathrm{liter}$ for benzimidazole. Plant hormones were added to agar medium following autoclaving but immediately before dispensing. Nonamended agar medium was used as a control. Petri dishes with leaf pieces on amended medium and nonamended control were sealed and incubated at $25^{\circ} \mathrm{C}$ under 12/12-h light/dark cycle. Petri dishes in the incubator were arranged in a completely randomized design with three replications, and the experiment was conducted twice. Leaves were rated for percentage of green color against a color chart from 4 days until 52 days after leaf plating, using a 1 to 9 chlorosis scale (M. Twizeyimana, unpublished data) in which $1=0$ to $5 \%$ chlorosis (i.e., 95 to $100 \%$ green color), $2=5$ to $20 \%, 3=20$ to $30 \%, 4=30$ to $40 \%, 5=40$ to $50 \%, 6=50$ to $60 \%, 7=60$ to $70 \%, 8=$ 70 to $80 \%$, and $9=>80 \%$ chlorosis.

In the second experiment, we evaluated ability of the detached leaf method to screen genotypes for resistance to $M$. $f i$ jiensis. Leaves of Agbagba, Calcutta-4, FHIA-23, FHIA-25, PITA-21, PITA-17, TMB2 $\times 25291-S 26$, and TM3 $\times 26388-1$ were obtained from the IITA farm in Ibadan. For each cultivar, two leaf pieces measuring $4 \mathrm{~cm}$ long $\times 3 \mathrm{~cm}$ wide, obtained as described above, were placed in plastic petri dishes with adaxial side on agar amended with $5 \mathrm{mg} /$ liter gibberellic acid. Gibberellic acid was used in the medium for the detached leaf assay based on its ability to keep leaves green for the entire duration of leaf assessment. Inoculum was prepared as described above; prior to inoculation, a drop of $1 \%$ Triton X-100 was added to the spore suspension. Leaf pieces were inoculated (two droplets per leaf piece) by pipetting $40-\mu 1$ droplets of spore suspension $\left(5 \times 10^{5} \mathrm{conidial} / \mathrm{ml}\right)$ on the abaxial side of the leaf. The petri plates were then sealed with Parafilm and transferred to an incubator at $25^{\circ} \mathrm{C}$ with $12 / 12$-h light/dark cycle. Plates in the incubator were arranged in a completely randomized design with three replications, and the 
experiment was conducted twice. Observations on inoculated detached leaves started 2 days after inoculation and lasted 32 days. Data were recorded on incubation time, leaf area infected, symptom evolution time, and symptom stages.

Statistical analysis. Temporal disease data from each replication were fitted to a linear model, $y=y_{0}+r x$ ( $y_{0}$ and $r$ are parameters to be estimated), as described by Neher et al. (22), to estimate the rates of disease progress $(r)$ on each cultivar inoculated with mycelial fragments and conidia. For each cultivar, estimates of $r$ were compared among inoculum types by the ANOVA procedure of SAS (version 9.1, SAS Institute, Cary, NC), and mean rates of disease progress were separated with Fisher's protected least significant difference (LSD) test at $\alpha=0.05$. ANOVA was performed on final disease severity of each cultivar, and means were separated using LSD. The influence of plant hormones on maintaining the green color of detached leaves over time was analyzed by repeated measures analysis of variance with the SAS GLM procedure. Data on disease variables obtained in cultivar resistance experiments were analyzed using GLM, and means were separated using the Student-Newman-Keuls test at $\alpha=0.05$. Spearman rank correlation was used to determine whether the ranking of cultivars by in vitro plantlets in tubes and detached leaf assays was consistent for incubation time and leaf area infected. Since symptom stages were ordinal values, the Wilcoxon rank sum test using the NPAR1WAY procedure in SAS was used to determine whether the two screening assays ranked cultivars consistently using this disease variable. A paired sample $t$ test was conducted to examine whether there was a difference between incubation time and leaf area infected recorded from the in vitro plantlet and the detached leaf assays.

\section{RESULTS}

Evaluation of $M$. fijiensis inoculum. Leaves of in vitro plantlets of four Musa cultivars were inoculated with mycelial and conidial suspensions to determine how inoculum type and concentration affect disease development. Disease severity was consistently higher on cultivars inoculated with mycelial fragments and consistently lower when cultivars were inoculated with a $1 \times 10^{4}$ conidial $/ \mathrm{ml}$ spore suspension. Disease severity levels were intermediate when cultivars were inoculated with $5 \times$ $10^{5}$ conidial/ml (Fig. 1). Similarly, when disease severity data were fitted to a linear model, rates of disease progress were significantly $(P<0.05)$ higher for mycelial fragments and lower for $1 \times 10^{4}$ conidia/ml, irrespective of cultivar (Table 2 ). Final disease severity levels were also consistently higher when plantlets were inoculated with mycelial fragments and lower for $1 \times 10^{4}$ conidia/ml (Fig. 2). Cal-
Table 2. Rates ${ }^{y}$ of black leaf streak progress on in vitro plantlets in tubes of Musa cultivars inoculated with different types of Mycosphaerella fijiensis inoculum

\begin{tabular}{lcccc}
\hline & \multicolumn{4}{c}{ Musa cultivars $^{\mathbf{z}}$} \\
\cline { 2 - 5 } Inoculum type & Agbagba & FHIA-23 & PITA-17 & Calcutta-4 \\
\hline Mycelial fragments & $3.95(94 \%)$ & $3.18(96 \%)$ & $0.91(92 \%)$ & $0.78(93 \%)$ \\
Conidia suspension $\left(5 \times 10^{5}\right)$ & $1.63(90 \%)$ & $1.01(90 \%)$ & $0.66(90 \%)$ & $0.29(93 \%)$ \\
Conidia suspension $\left(1 \times 10^{4}\right)$ & $0.48(91 \%)$ & $0.42(90 \%)$ & $0.18(94 \%)$ & $0.08(96 \%)$ \\
LSD $(P=0.05)$ & $0.03(91 \%)$ & $0.05(90 \%)$ & $0.04(94 \%)$ & $0.01(96 \%)$ \\
\hline
\end{tabular}

${ }^{\mathrm{y}}$ Rates of disease progress are based on fitting a linear regression equation $\left(y=y_{0}+r x\right)$ to disease severity data, where $y=$ leaf area infected (\%), $x=$ time (days after inoculation), and $y_{0}$ and $r$ are parameters to be estimated. Values in parentheses refer to the coefficient of determination $\left(R^{2}\right)$ of goodness of fit to the linear equation based on untransformed data.

${ }^{\mathrm{z}}$ Agbagba and Calcutta-4 are the highly susceptible and resistant cultivars, respectively.

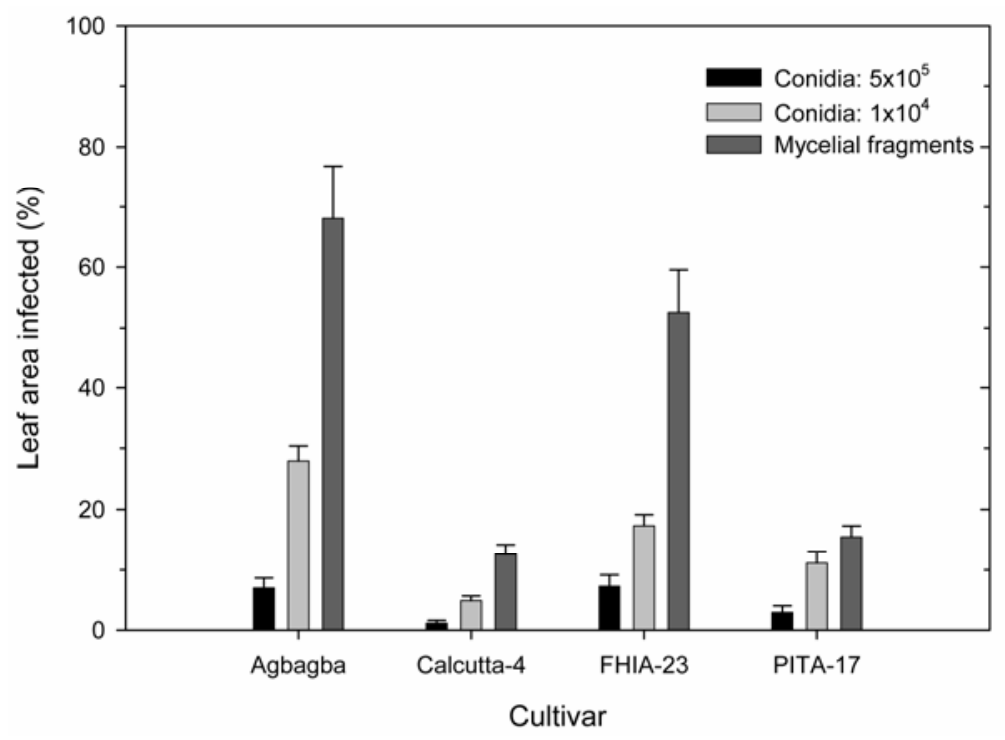

Fig. 2. Effect of different types of Mycosphaerella fijiensis inoculum on disease severity of four Musa cultivars with different levels of susceptibility to black leaf streak. Disease severity was assessed on in vitro plantlets in tubes 32 days after inoculation. For each vertical bar, vertical lines represent the standard error of the mean.

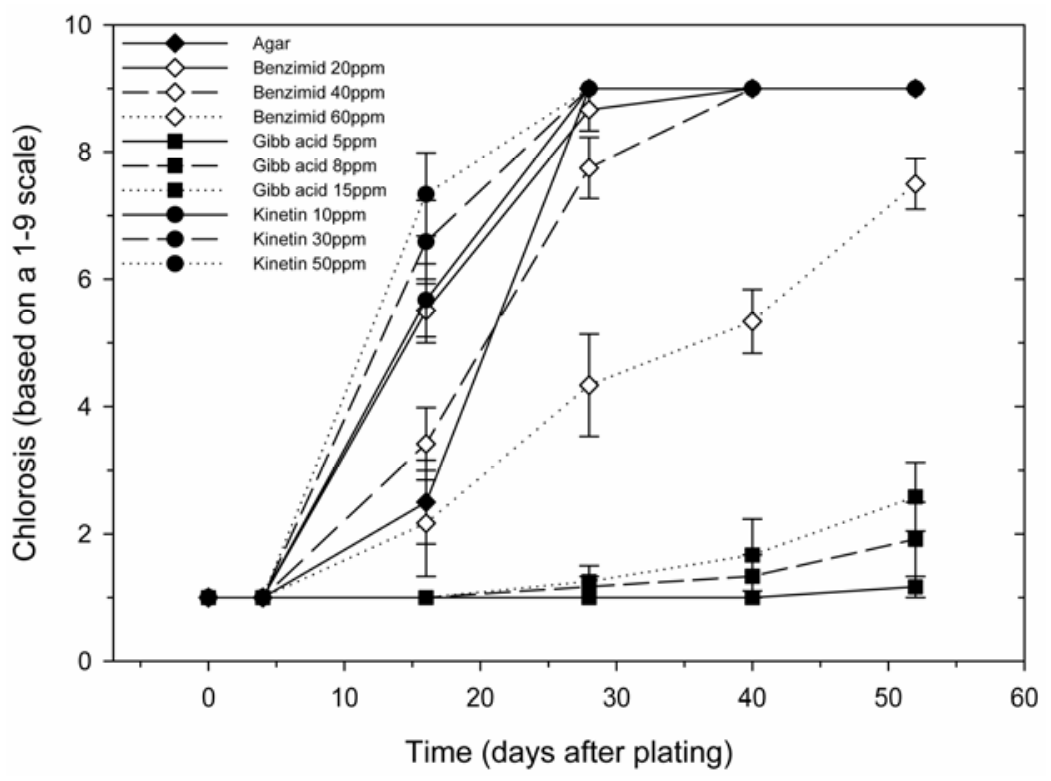

Fig. 3. Effect of agar media amended with different concentrations of plant hormones in maintaining green color in detached leaves of cultivar Agbagba. For each concentration, vertical bars represent standard errors of mean chlorosis. Benzimid and Gibb acid refer to benzimidazole and gibberellic acid, respectively. 
cutta-4 (highly resistant) had a significantly $(P<0.0001)$ lower final disease severity than Agbagba, irrespective of the type of inoculum. Leaves inoculated with sterile distilled water did not show any disease symptoms. Due to difficulties associated with quantifying the concentration of mycelial fragments, we thereafter used $5 \times 10^{5}$ conidia/ml in all subsequent inoculations.

Evaluation of amended media on detached leaves. Area of green leaf color was used as a measure of deterioration of detached leaves over time. The ability of hormone-amended agar media to maintain green color in detached leaves varied significantly $(P<0.0001)$, with distinct differences observed as early as 5 days after plating (Fig. 3). The amount of chlorosis 16 days after plating on media amended with gibberellic acid was $\leq 5 \%$, which was significantly $(P<0.05)$ lower than that of all other plant hormones. Twenty-eight days after plating, the amount of chlorosis in leaves for all plant hormones was $>30 \%$, except for gibberellic acid for which the level of chlorosis was about $5 \%$. When the study was terminated 52 days after plating, the amount of chlorosis in leaves plated on medium amended with $5 \mathrm{mg} /$ liter gibberellic acid was still $<5 \%$ and was significantly $(P<0.0001)$ lower than for all other plant hormones except gibberellic acid with a concentration of $8 \mathrm{mg} / \mathrm{liter}$.

Evaluation of in vitro plantlet assay and detached leaves for resistance screening. Disease progressed more rapidly on in vitro plantlets than on detached leaves (Fig. 4), and disease severity was higher and lower in the in vitro and the detached leaf assay, respectively. For example, Agbagba had about disease severity levels of 81 and $31 \%$ when evaluated using in vitro plantlets and detached leaf assays, respectively, 32 days after inoculation. In both assays, disease severity assessed 32 days after inoculation separated cultivars based on resistance (Fig. 4). When evaluated for resistance to $M$. fijiensis using either assay, genotypes significantly $(P<$ $0.001)$ affected incubation time, symptom evolution time, disease severity, and symp-
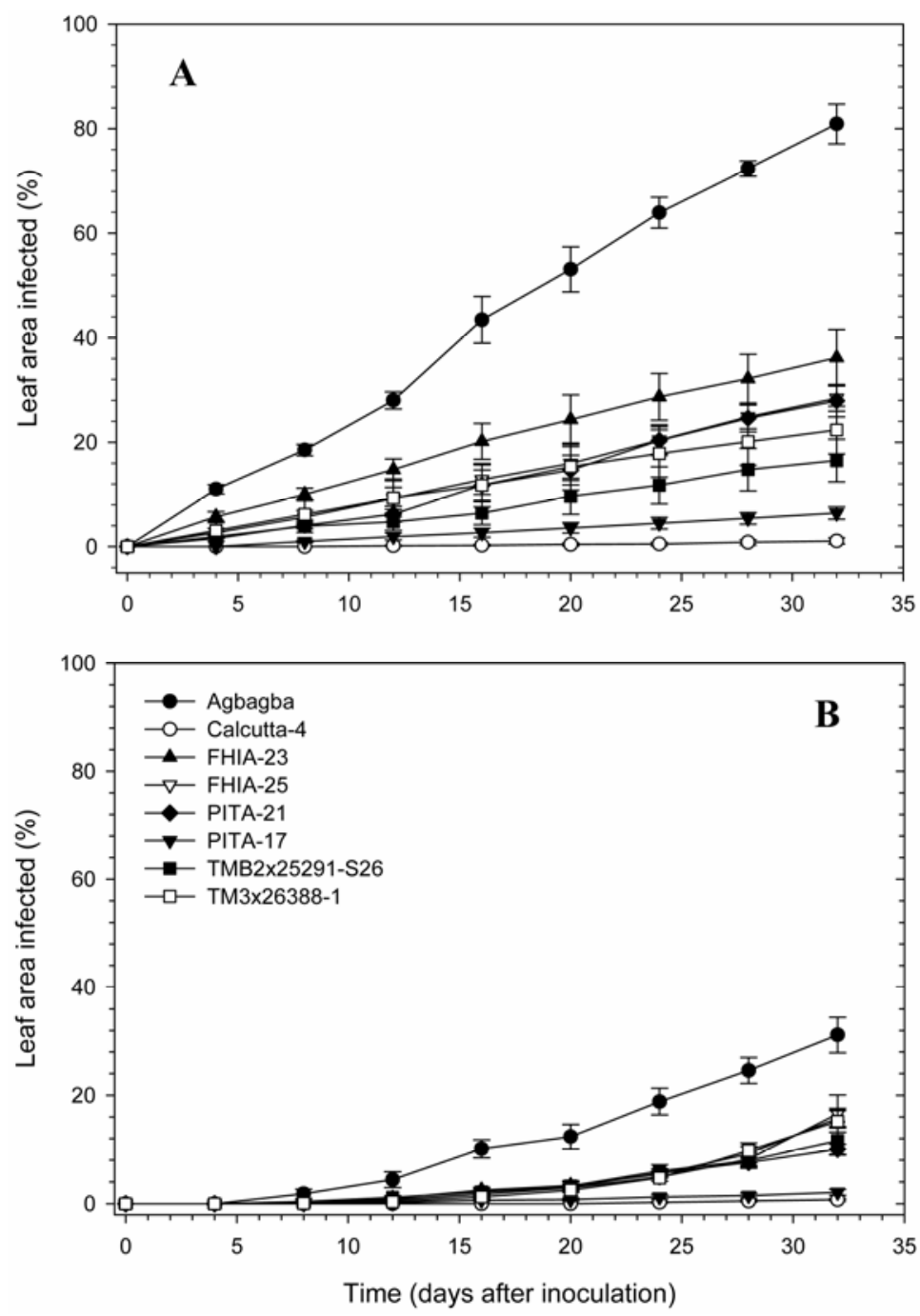

Fig. 4. Temporal progress of black leaf streak on in vitro plantlets in tubes (A) and detached leaves (B) inoculated with conidial suspension of Mycosphaerella fijiensis at $5 \times 10^{5}$ conidia/ml. Vertical bars represent standard error of the means for each cultivar on each assessment date. tom stages. Resistant cultivars had significantly $(P=0.001)$ longer incubation times and lower disease severity levels than susceptible cultivars (Table 3 ).

Unlike in the in vitro assay, cultivars did not complete the SET in the detached leaf assay, but a consistent pattern was observed in both assays, with susceptible cultivars such as Agbagba having a significantly $(P<0.05)$ shorter symptom evolution time or days to stage 4 (for detached leaf assay) than the moderately resistant cultivars. Disease severity was not significantly $(P=0.2817$ for two-tailed $t$ test $)$ different when assessed using the two assays. In addition, Spearman's rank correlation showed that disease severity in the two assays were strongly correlated ( $r=$ $0.88, n=48, P<0.0001)$. Although incubation time was significantly $(P=0.0062$ for two-tailed $t$ test) different between the two assays, Spearman's rank correlation indicated a strong correlation between the two assays ( $r=0.69, n=48, P<0.0001)$.

Each symptom stage was observed much earlier on in vitro plantlets than on detached leaves (Table 4), irrespective of the cultivar evaluated. After 20 and 32 days after inoculation, highly significant $(P<0.0001)$ differences in symptom stages were observed between the two assays. Ranking of cultivars based on symptom stage was similar for both assays, with susceptible and moderately resistant cultivars having correspondingly more advanced symptom stages compared with resistant cultivars, except at 6 days after inoculation (Table 4).

\section{DISCUSSION}

We evaluated two assays for rapid and mass screening of Musa cultivars for resistance to black leaf streak. Direct inoculation of in vitro plantlets in tubes and detached leaf assays consistently ranked cultivars relative to their corresponding levels of resistance to $M$. fijiensis. These two assays that are fast, space-effective, and accurate can be new tools for highthroughput screening of Musa spp. against black leaf streak.

One of the difficulties in breeding Musa spp. for black leaf streak resistance has been the screening process, with field evaluation being the principal procedure $(19,23,24)$. However, field screening has limitations, since it depends on the presence of proper environmental conditions, can often be carried out only once a year, and is time-consuming and expensive. Direct inoculation of in vitro plantlets in tubes and inoculation of detached leaves in moist chambers are two assays that overcome the limitations associated with field and other early screening evaluations.

Detached leaves have been used primarily for screening for rusts $(1,3,12)$ and other diseases $(8,13,14,29)$. Prior to this report, no studies had been conducted to evaluate the use of this assay for screening 
Musa spp. for resistance to black leaf streak. A critical aspect of this assay is the prevention of senescence of leaf pieces before the duration required to express symptom stages and disease severity levels necessary to differentiate among cultivar responses (29). Benzimidazole (1) and cytokinin (3) have been used in the incubation medium to prevent chlorophyll degradation in detached leaves (2). Our results indicate that agar medium amended with 5 $\mathrm{mg} /$ liter gibberellic acid is able to retard chlorophyll degradation up to 52 days after plating. Although Xie and Mew (29) observed that addition of benzimidazole to water agar was adequate in conserving freshness of rice leaves, our study shows that gibberellic acid is the most effective hormone in maintaining green color in banana leaves.

Based on our results, a spore concentration of $5 \times 10^{5}$ conidia/ml was adopted for inoculation of in vitro plantlets in tubes and detached leaves. Although mycelial fragments resulted in higher disease severity and infection rates than conidial suspensions, the difficulty of standardizing the concentration of mycelial fragments makes mycelia unsuitable for in vitro inoculation. Capó et al. (4) argued that mycelial fragments can be produced in a short period of time and at different periods of the year, which circumvents the loss of conidia production on culture media by some $M$. fijiensis isolates. In this study, no loss of conidia was observed in culture plates until after 3 weeks following sporulation.

Disease development on in vitro plantlets and detached leaves were well correlated, and cultivars were consistently ranked using the two assays. Symptoms appeared much earlier when cultivars were screened using in vitro plantlets than detached leaves, as indicated by the significant difference in incubation time between the two assays. The shorter incubation times observed on in vitro plantlets may be related to the age of in vitro tissues, which are much more tender with limited secondary thickening as opposed to detached leaves from the field. Symptom appearance on in vitro plantlets differed from that observed on older plants in the field $(4,21)$. Primarily, spots were slightly circular, possibly because young plants derived from tissue culture have limited vein development and black leaf streak lesions tend to be spherical (20). Although a paired analysis of disease severity indicated no significant difference between the two assays, this difference in morphology of the tissues may also explain the higher severity levels observed on in vitro plantlets compared with the detached leaves for a similar set of cultivars. Higher disease severity on young tissue culture plants has been reported previously (19).

Table 4. Symptom stages of Mycosphaerella fijiensis on Musa cultivars on three assessment periods evaluated using in vitro plantlets in tubes and detached leaves ${ }^{\mathrm{x}}$

\begin{tabular}{lcccccccc}
\hline & \multicolumn{3}{c}{ Plantlets in tubes } & & \multicolumn{3}{c}{ Detached leaves } \\
\cline { 2 - 4 } \cline { 7 - 8 } Cultivar $^{\mathbf{y}}$ & $\mathbf{6}$ days & $\mathbf{2 0}$ days & $\mathbf{3 2}$ days & & $\mathbf{6}$ days & $\mathbf{2 0}$ days & $\mathbf{3 2}$ days \\
\hline Agbagba & 3 & 6 & 6 & & NS & 4 & 5 \\
FHIA-23 & 3 & 5 & 6 & & NS & 2 & 4 \\
PITA-21 & 1 & 4 & 6 & & NS & 3 & 4 \\
TMB2 $\times 24203-14$ & 1 & 4 & 6 & & $\ldots$ & $\ldots$ & $\ldots$ \\
TMB2 $\times 25291-S 26$ & 1 & 4 & 6 & & NS & 3 & 4 \\
TM3 $\times 26388-1$ & 2 & 4 & 6 & & NS & 2 & 4 \\
FHIA-25 & 2 & 5 & 6 & & NS & 2 & 5 \\
TMB2 $\times 25291-S 44$ & 1 & 4 & 6 & & $\ldots$ & $\ldots$ & $\ldots$ \\
PITA-17 & 1 & 2 & 3 & & NS & 1 & 3 \\
Calcutta-4 & NS & 1 & 2 & & NS & NS & 1 \\
\hline
\end{tabular}

${ }^{\mathrm{x}} \mathrm{NS}$ denotes no symptoms were observed on the respective cultivar. Symptom stages were based on the 1-6 Fouré scale (9) in which stage $1=$ minute yellowish specks, less than $1 \mathrm{~mm}$ long only seen on the lower leaf surface and not visible in translucent light; $2=$ specks are 2-4 $\mathrm{mm}$ long, brown and visible in translucent light; $3=$ brown specks elongate, with streaks reaching $2-3 \mathrm{~cm} ; 4=$ broader, round or elliptical spots, brown underneath and black on the leaf surface; $5=$ spots are totally black, surrounded by a yellow halo; and $6=$ center of spots dries out and fades to gray and a black ring surrounds the yellow halo.

y Agbaba and Calcutta-4 are the highly susceptible and resistant check cultivars, respectively.

${ }^{\mathrm{z}}$ TMB $2 \times 25291-\mathrm{S} 44$ and TMB2 $\times 24203-14$ cultivars were not evaluated using the detached leaf assay.

Table 3. Incubation time, symptom evolution time, and leaf area infected due to black leaf streak on Musa cultivars evaluated using in vitro plantlets in tubes and detached leaves

\begin{tabular}{|c|c|c|c|c|c|c|}
\hline \multirow[b]{2}{*}{ Cultivarw } & \multicolumn{3}{|c|}{ Plantlets in tubes ${ }^{v}$} & \multicolumn{3}{|c|}{ Detached leaves ${ }^{v}$} \\
\hline & $\begin{array}{l}\text { Incubation } \\
\text { time (days) }\end{array}$ & $\begin{array}{c}\text { Symptom evolution } \\
\text { time (days) }\end{array}$ & $\begin{array}{c}\text { Leaf area } \\
\text { infected }(\%)\end{array}$ & $\begin{array}{l}\text { Incubation } \\
\text { time (days) }\end{array}$ & $\begin{array}{l}\text { Days to } \\
\text { stage } 4^{\mathrm{x}}\end{array}$ & $\begin{array}{c}\text { Leaf area } \\
\text { infected }(\%)\end{array}$ \\
\hline Agbagba & $5.3 \mathrm{c}$ & $16.7 \mathrm{c}$ & $80.9 \mathrm{a}$ & $7.8 \mathrm{~d}$ & $20.3 \mathrm{~b}$ & $31.2 \mathrm{a}$ \\
\hline FHIA-23 & $6.2 \mathrm{c}$ & $24.7 \mathrm{~b}$ & $36.2 \mathrm{~b}$ & $12.0 \mathrm{~cd}$ & $29.3 \mathrm{a}$ & $15.8 \mathrm{~b}$ \\
\hline FHIA-25 & $6.5 \mathrm{c}$ & $29.3 \mathrm{a}$ & $28.4 \mathrm{bc}$ & $15.3 \mathrm{c}$ & $29.3 \mathrm{a}$ & $16.6 \mathrm{~b}$ \\
\hline PITA-21 & $7.3 \mathrm{bc}$ & $30.6 \mathrm{a}$ & $27.9 \mathrm{bc}$ & $13.3 \mathrm{~cd}$ & $28.7 \mathrm{a}$ & $10.0 \mathrm{~b}$ \\
\hline TMB $2 \times 25291-S 44$ & $7.0 \mathrm{bc}$ & $31.5 \mathrm{a}$ & $23.2 \mathrm{bc}$ & $\ldots{ }^{y}$ & & \\
\hline TM3 × 26388-1 & $8.0 \mathrm{bc}$ & $28.7 \mathrm{a}$ & $22.3 \mathrm{bc}$ & $15.3 \mathrm{c}$ & $29.7 \mathrm{a}$ & $15.2 \mathrm{~b}$ \\
\hline TMB2 $\times 24203-14$ & $7.3 \mathrm{bc}$ & $31.3 \mathrm{a}$ & $19.8 \mathrm{c}$ & $\ldots y$ & & \\
\hline TMB $2 \times 25291-S 26$ & $8.8 \mathrm{bc}$ & $30.0 \mathrm{a}$ & $16.5 \mathrm{dc}$ & $11.7 \mathrm{~cd}$ & $27.7 \mathrm{a}$ & $15.0 \mathrm{~b}$ \\
\hline PITA-17 & $12.3 \mathrm{~b}$ & $\ldots^{\mathrm{z}}$ & $6.4 \mathrm{de}$ & $22.0 \mathrm{~b}$ & $\ldots^{\mathrm{z}}$ & $2.1 \mathrm{c}$ \\
\hline Calcutta-4 & $27.3 \mathrm{a}$ & $\ldots{ }^{z}$ & $1.1 \mathrm{e}$ & $29.3 \mathrm{a}$ & $\ldots^{\mathrm{z}}$ & $0.8 \mathrm{c}$ \\
\hline
\end{tabular}

${ }^{\mathrm{v}}$ Within each column, mean values followed by similar letters are not significantly different $(P \leq 0.05)$ by Student-Newman-Keuls test.

${ }^{\text {w }}$ Agbaba and Calcutta- 4 are the highly susceptible and resistant check cultivars, respectively.

${ }^{x}$ All cultivars evaluated using detached leaf technique did not complete their symptom evolution time; and thus, number of days to stage 4 was recorded instead.

y TMB2 $\times 25291-S 44$ and TMB $2 \times 24203-14$ cultivars were not evaluated using detached leaves.

${ }^{\text {z }}$ Calcutta-4 and PITA-17 did not complete their symptom evolution times when evaluated using in vitro plantlets; and similarly, symptoms did not reach stage 4 when evaluated using the detached leaf technique. 
greenhouse and field screening methods, and may be employed for mass screening of Musa spp. to facilitate black streak resistance breeding. Of course, genotypes identified as resistant based on these rapid screening methods have to be evaluated under field conditions as the final confirmatory test. We are currently using the detached leaf assay to phenotype several progenies of two mapping populations to identify QTL for black leaf streak resistance. The detached leaf technique is also being used to determine the pathogenicity potential of more than 400 isolates of $M$. fijiensis on Musa genotypes in Nigeria.

\section{ACKNOWLEDGMENTS}

This work was funded in part by the Directorate General for Development Cooperation (DGDC), Belgium. We thank Francis Moonan, IITA, for providing tissue culture plants.

\section{LITERATURE CITED}

1. Asnaghi, C., D'Hont, A., Glaszmann, J. C., and Rott, P. 2001. Resistance of sugarcane cultivar R 570 to Puccinia melanocephala isolates from different geographic locations. Plant Dis. 85:282-286.

2. Browder, L. E. 1964. A modified detached leaf culture technique for study of cereal rusts. Plant Dis. Rep. 48:906-908.

3. Browne, R. A., Murphy, J. P., Cooke, B. M., Devaney, D., Walsh, E. J., Griffey, C. A., Hancock, J. A., Harrison, S. A., Hart, P., Kolb, F. L., McKendry, A. L., Milus, E. A., Sneller, C., and Van Sanford, D. A. 2005. Evaluation of components of Fusarium head blight resistance in soft red winter wheat germ plasm using a detached leaf assay. Plant Dis. 89:404-411.

4. Capó, Y. A., Mora, M. L., Rodríguez, M. A. D., Acosta, M., Cruz, M., Portal, N., Kosky, R. G., García, L., Bermúdez, I., and Padrón, J. 2003. Early evaluation of black leaf streak resistance by using mycelial suspensions of Mycosphaerella fijiensis. Pages 169-175 in: Mycosphaerella Leaf Spot Diseases of Bananas: Present Status and Outlook. L. Jacome, P. Lepoivre, D. Marín, R. Ortiz, R. Romero, and J. V. Escalant, eds. Proc Int. Workshop on Mycosphaerella Leaf Spot Diseases, 2nd, San José, Costa Rica, 20-23 May 2002. INIBAP, Montpellier, France.

5. Carlier, J., Fouré, E., Gauhl, F., Jones, D. R., Lepoivre, P., Mourichon, X., Pasberg-Gauhl, C., and Romero, R. A. 2000. Sigatoka leaf spots: Black leaf streak. Pages 37-77 in: Diseases of Banana, Abacá and Enset. D. R. Jones, ed. CAB International, Wallingfold, UK.

6. Chin, K. M., Wirz, M., and Laird, D. 2001. Sensitivity of Mycosphaerella fijiensis from banana to trifloxystrobin. Plant Dis. 85:12641270.

7. Craenen, K., and Ortiz, R. 1998. Influence of black Sigatoka disease on the growth and yield of diploid and tetraploid hybrids. Crop Prot. 17:13-18.

8. Foolad, M. R., Ntahimpera, N., Christ, J. B., and Yin, G. Y. 2000. Comparison of field, greenhouse, and detached-leaflet evaluation of tomato germ plasm for early blight resistance. Plant Dis. 84:967-972.

9. Fouré, E. 1987. Varietal reactions of banana and plantains to black leaf streak disease. Pages 110-113 in: Banana and Plantain Breeding Strategies. G. J. Persley and E. de Langhe, eds. ACIAR Proc. No. 21, Canberra, Australia.

10. Fouré, E. 1990. Contribution to genetic control of banana and plantain Sigatoka leaf spot in Cameroon: Studies on varietal susceptibility and early inoculation trials on plantlets produced by in vitro culture. Pages 290-305 in: Sigatoka Leaf Spot Diseases of Bananas. R. A. Fullerton and R. H. Stover, eds. Proc. Int. Workshop, San José, Costa Rica, March 28April 1, 1989. INIBAP, Montpellier, France.

11. Harelimana, G., Lepoivre, P., Jijakli, H., and Mourichon, X. 1997. Use of Mycosphaerella fijiensis toxins for the selection of banana cultivars resistant to black leaf streak. Euphytica 96:125-128.

12. Herath, I. H. M. H. B., Stoddard, F. L., and Marshall, D. R. 2001. Evaluating faba beans for rust resistance using detached leaves. Euphytica 117:47-57.

13. Huang, S., Vleeshouwers, V. G. A. A., and Jacobsen, E. 2005. An accurate in vitro assay for high-throughput disease testing for Phytophthora infestans in potato. Plant Dis. 89:1263-1267.

14. Jia, Y., Valent, B., and Lee, F. E. 2003. Determination of host responses to Magnaporthe grisea on detached rice leaves using a spot inoculation method. Plant Dis. 87:129-133.

15. Marín, D. H., and Romero, R. A. 1992. El combate de la Sigatoka negra. Boletín No. 4, Departamento de Investigaciones, Corporación Bananera Nacional, Costa Rica.

16. Marín, D. H., Romero, R. A., Guzmán, M., and Sutton, T. B. 2003. Black Sigatoka: An increasing threat to banana cultivation. Plant Dis. 87:208-222.

17. Mobambo, K. N., Gauhl, F., Vuylsteke, D.,
Ortiz, R., Pasberg-Gauhl, C., and Swennen, R. 1993. Yield loss in plantain from black sigatoka leaf spot and field performance of resistant hybrids. Field Crops Res. 35:35-42.

18. Mobambo, K. N., Pasberg-Gauhl, C., Gauhl, F., and Zuofa, K. 1994. Early screening for black leaf streak/black Sigatoka under natural inoculation conditions. Infomusa 3:4-16.

19. Mobambo, K. N., Pasberg-Gauhl, C., Gauhl, F., and Zuofa, K. 1997. Host response to black sigatoka in Musa germplasm of different ages under natural inoculation conditions. Crop Prot. 16:359-363.

20. Mourichon, X., Lepoivre, P., and Carlier, J. 2000. Host-pathogen interactions. Pages 67-72 in: Diseases of Banana, Abacá and Enset. D. R. Jones, ed. CAB International, Wallingfold, UK.

21. Mourichon, X., Peter, D., and Zapater, M. 1987. Inoculation expérimentale de $M y$ cosphaerella fijiensis Morelet sur de jeunes plantules de bananiers issues de culture in vitro. Fruits 42:195-198.

22. Neher, D. A., Reynolds, K. L., and Campbell, C. L. 1997. Analysis of disease progress curves using linear models. Pages 29-33 in: Exercises in Plant Disease Epidemiology. L. J. Francl and D. A. Neher, eds. American Phytopathological Society, St. Paul, MN.

23. Nwauzoma, A. B., Tenkouano, A., Crouch, J. H., Pillay, M., Vuylsteke, D., and Daniel Kalio, L. A. 2002. Yield and disease resistance of plantain (Musa spp., AAB group) somaclones in Nigeria. Euphytica 123:323-331.

24. Oluma, H. O. A., Onekutu, A., and Onyezili, F. N. 2003. Reactions of plantain and banana cultivars to black sigatoka leaf spot disease in three farming systems in Nigerian guinea savanna. J. Plant Dis. Prot. 111:158-164.

25. Romero, R. A., and Sutton, T. B. 1997. Reaction of four Musa genotypes at three temperatures to isolates of Mycosphaerella fijiensis from different geographical regions. Plant Dis. 81:1139-1142.

26. Stover, R. H. 1976. Distribution and cultural characteristics of the pathogens causing banana leaf spot. Trop. Agric. (Trinidad) 53:111114.

27. Stover, R. H. 1980. Sigatoka leaf spot of banana and plantain. Plant Dis. 64:750-756.

28. Vuylsteke, D. R. 1998. Shoot-tip Culture for the Propagation, Conservation, and Distribution of Musa Germplasm. International Institute of Tropical Agriculture, Ibadan, Nigeria.

29. Xie, G. L., and Mew, T. W. 1998. A leaf inoculation method for detection of Xanthomonas oryzae pv. oryzicola from rice seed. Plant Dis. 82:1007-1011. 